\title{
Isolamento, caracterização e diferenciação de células-tronco mesenquimais do líquido amniótico equino obtido em diferentes idades gestacionais ${ }^{1}$
}

\author{
Bruna De Vita ${ }^{2 *}$, Loreta L. Campos ${ }^{2}$, Amanda J. Listoni² ${ }^{2}$ Leandro Maia ${ }^{3}$, Mateus J. \\ Sudano $^{2}$, Bruna R. Curcio ${ }^{4}$, Fernanda C. Landim-Alvarenga ${ }^{2}$ e Nereu C. Prestes ${ }^{2}$
}

\begin{abstract}
De Vita B., Campos L.L., Listoni A.J., Maia L., Sudano M.J., Curcio B.R., Landim-Alvarenga F.C. \& Prestes N.C. 2013. [Isolation, characterization and differentiation of mesenchymal stem cells derived from equine amniotic fluid obtained from different gestacional ages.] Isolamento, caracterização e diferenciação de células-tronco mesenquimais do líquido amniótico equino obtido em diferentes idades gestacionais. Pesquisa Veterinária Brasileira 33(4):535-542. Departamento de Reprodução Animal e Radiologia Veterinária, Faculdade de Medicina Veterinária e Zootecnia, Universidade Estadual Paulista, Distrito de Rubião Júnior s/n, Botucatu, SP 18618-970, Brazil. E-mail: bruddev@gmail.com

The interest in stem cells derived from fetal annexes of many species has exponentially increased during the last decades, because they are adult stem cell sources with potential of differentiation in several cell lineages; which present little or no immunogenicity and are an alternative with great importance for storage cell banks. Despite the rising interest, studies for the equine species are still rare. The aim of this study was to isolate, characterize and differentiate mesenchymal stem cells derived from equine amniotic fluid obtained from initial, middle and late third of gestation (AF-MSCs), and compare their results. Twenty three samples from equine amniotic fluid were evaluated by morphological, immunocytochemical and immunophenotypical (Flow cytometer) assays and osteogenic, adipogenic and chondrogenic in vitro differentiation. All samples demonstrated plastic adhesion and fibroblastoid morphology. The immunocytochemical assay demonstrated cells from all the studied groups were positive for CD44, PCNA and vimentin and negative for cytokeratin and Oct-4. Flow cytometry demonstrated expression of CD44 and CD90 and no expression of CD34, where CD44 and CD90 markers presented decreasing pattern of expression in relation to the gestational development. All samples collected from all gestational phases were capable to differentiate in osteogenic, chondrogenic and adipogenic lineages. Thus, cells obtained from equine amniotic fluid presented morphological and immunophenotypical characteristics and potential of differentiation typical of MSCs showing that the collection can be performed at any stage of pregnancy. However, more studies should be performed about the expression of pluripotent markers as Oct- 4 and the differentiation potential for extra mesodermal lineages prior demonstrated in the literature.
\end{abstract}

INDEX TERMS: Equine, fetal annexes, mesenchymal stem cells, imunocytochemistry, flow citometry.

\footnotetext{
${ }^{1}$ Recebido em 19 de setembro de 2012.

Aceito para publicação em 18 de fevereiro de 2013.

${ }^{2}$ Departamento de Reprodução Animal e Radiologia Veterinária, Faculdade de Medicina Veterinária e Zootecnia (FMVZ), Universidade Estadual Paulista (Unesp), Distrito de Rubião Júnior s/n, Botucatu, SP 18618-970, Brasil. *Autor para correspondência: bruddev@gmail.com

${ }^{3}$ Departamento de Clínica Veterinária, FMVZ-Unesp, Botucatu, SP.

${ }^{4}$ Departamento de Clínicas Veterinárias, Faculdade de Medicina Veterinária (FMV), Universidade Federal de Pelotas (UFPel), Rua Gomes Carneiro 1, Centro, Pelotas, RS 96010-610, Brasil.
}

RESUMO.- 0 interesse nas pesquisas com células-tronco derivadas de anexos fetais de diversas espécies cresceu exponencialmente nas últimas décadas em virtude de serem fontes de células-tronco adultas com potencial de diferenciação em diversas linhagens celulares que apresentam pouca ou nenhuma imunogenicidade, apresentando-se assim como alternativa de grande importância para a formação de bancos celulares. Apesar do crescente interesse, os estudos para espécie equina ainda são escassos. 0 objetivo 
deste trabalho foi isolar, caracterizar e diferenciar células-tronco mesenquimais (CTMs) derivadas do líquido amniótico equino obtidas do terço inicial, médio e final da gestação (LA-CTMs), comparando suas características. Foram colhidas 23 amostras de líquido amniótico as quais foram submetidas às análises morfológica, imunocitoquímica, imunofenotípica por citometria de fluxo e às diferenciações osteogênica, adipogênica e condrogênica in vitro. Todas as amostras demonstraram adesão ao plástico e morfologia fibroblastóide. No ensaio imunocitoquímico as células de todos os grupos foram imunomarcadas para CD44, PCNA e vimentina com ausência de marcação para citoqueratina e Oct-4. Na citometria de fluxo observou-se a expressão de CD44 e CD90 e ausência de expressão de CD34, sendo que os marcadores CD44 e CD90 mostraram padrão de expressão decrescente em relação ao desenvolvimento gestacional. As amostras obtidas de todas as fases da gestação foram capazes de diferenciação nas linhagens osteogênica, condrogênica e adipogênica. Portanto, as células obtidas do líquido amniótico apresentaram características morfológicas, imunofenotípicas e potencial de diferenciação típicos das CTMs, demonstrando que a colheita pode ser realizada em qualquer fase gestacional. No entanto, mais pesquisas devem ser realizadas principalmente quanto à expressão de marcadores de pluripotencialidade (como o Oct-4) e ao seu potencial de diferenciação em linhagens extra mesodermais já relatados na literatura.

TERMOS DE INDEXAÇÃO: Equino, anexos fetais, células-tronco mesenquimais, imunocitoquímica, citometria de fluxo.

\section{INTRODUÇÃO}

O líquido amniótico é formado por uma grande quantidade de células, de origem embrionária ou extra-embrionária, em suspensão. Esta população celular varia com a fase gestacional e traduz as mudanças ocorridas no feto e seus anexos, estando bastante vinculada com a maturidade fetal (Gosden 1983). As células apresentam tamanho de 6 a $50 \mu \mathrm{m}$, e morfologia também variável de escamosas a arredondadas (Bydlowski et al. 2009).

A detecção de células progenitoras no líquido amniótico humano foi inicialmente relatada em 1993 quando células arredondadas, pequenas e nucleadas, foram encontradas antes da $12^{\underline{a}}$ semana de gestação e identificadas como progenitoras hematopoiéticas, possivelmente provenientes da vesícula vitelínica (Torricelli et al. 1993). Hoje, sabe-se que três tipos celulares são encontrados no líquido amniótico: Células Epitelióides (E), com origem na pele e trato urinário do feto; Células Amnióticas (AF) propriamente ditas, originadas nas membranas placentárias e trofoblasto (produtoras de estrógenos, progesterona e gonadotrofina coriônica humana); e Fibroblatóides (F), originadas dos tecidos conjuntivos, apresenta características e marcadores para células-tronco mesenquimais (CTMs) e devem ser chamadas de CTMs derivadas do líquido amniótico (Gucciardo et al. 2008). As células dos tipos $\mathrm{AF}$ e $\mathrm{E}$ aparecem no início do cultivo enquanto as células $\mathrm{F}$ aparecem posteriormente, porém somente $\mathrm{AF} \mathrm{e}$ $\mathrm{F}$ persistem enquanto as células do tipo $\mathrm{E}$ regridem com o passar do tempo (Prusa \& Hengstschlager 2002).
A descoberta das CTMs derivadas do líquido amniótico humano, na última década, demonstrando a expressão do marcador de pluripotência Oct-4, alta capacidade de proliferação e potencial de diferenciação em diversas linhagens celulares, iniciou um novo e promissor campo na pesquisa de células-tronco (Siegel et al. 2007). Tsai et al. (2004) relataram a expressão de Oct-4 e a diferenciação in vitro nas linhagens osteogênica, adipogênica e neurogênica de CTMs obtidas do líquido amniótico (LA-CTMs) colhido no quarto mês de gestação de mulheres submetidas à amniocentese para avaliação citogenética do feto. No mesmo ano, Prusa e colaboradores relataram a expressão esporádica de marcadores neurogênicos pelas LA-CTMs e que esta expressão aumentou consideravelmente após o cultivo destas células sob meio de indução de diferenciação neurogênica. Em 2006, Tsai e colaboradores confirmaram a expressão de marcadores neurogênicos antes e após a indução da diferenciação e relataram ainda a expressão de mais um marcador de pluripotência, o NANOG-.

Muitos outros estudos descreveram a expressão de Oct4 (You et al. 2009, Steigman et al. 2009, Phermthai et al. 2010) e capacidade de diferenciação em muitas linhagens celulares (De Coppi et al. 2007, Peister et al. 2008, Antonucci et al. 2009, Cabral et al. 2009) tais como osteogênica, condrogênica, adipogênica, miogênica, neurogênica, endotelial e hepática das LA-CTMs humana. Além disso, as células não apresentaram alterações em seu cariótipo após o cultivo (Cabral et al., 2009), não induziram a formação de tumores quando foram transplantadas (You et al. 2009, Phermithai et al. 2010) e apresentaram $80 \%$ de viabilidade após 5 meses de criopreservação (Steigman et al. 2008). Apesar da grande maioria das pesquisas serem realizadas com amostras colhidas durante a amniocentese para ensaio citogenético dos fetos no quarto mês de gestação, estudos realizados com amostras colhidas durante a cesariana a termo obtiveram o mesmo padrão de resultados (Steigman et al. 2009, You et al. 2009).

Na medicina veterinária equina, o isolamento e caracterização de LA-CTMs de amostras colhidas durante o parto foram descritos recentemente. A população de LA-CTMs demonstrou ter maior taxa de crescimento e proliferação do que as populações de CTMs da medula óssea e do tecido extra vascular do cordão umbilical (Wharton's Jelly). Estas células apresentaram capacidade de diferenciação para as linhagens adipogênica, osteogênica e condrogênica, bem como outra característica marcante: a expressão de marcadores de pluripotência como o Oct-4 (Lovati et al. 2011). Park et al. (2011) também relataram êxito no isolamento de LA-CTMs equina, demonstrando alta taxa de proliferação, expressão de marcadores típicos de CTMs e capacidade de diferenciação em três diferentes linhagens celulares.

Os resultados encontrados na medicina humana indicando as LA-CTMs como uma fonte providencial e conveniente de células-tronco e a escassez de pesquisas encontradas na medicina veterinária equina sobre este assunto, motivaram a realização do presente estudo visando à otimização da obtenção de LA-CTMs equina e buscando estabelecer o melhor momento para colheita em fases gestacionais, possibilitando a utilização de úteros gravídicos 
considerados como descarte em frigoríficos comerciais como fonte para a formação de bancos de armazenamento. Sendo assim, o objetivo deste trabalho foi isolar, cultivar, caracterizar imunofenotipicamente e avaliar a capacidade de diferenciação in vitro nas linhagens osteogênica, adipogênica e condrogênica de CTMs derivadas do líquido amniótico equino obtidos dos terços inicial, médio e final da gestação, comparando os resultados encontrados entre os grupos estudados.

\section{Colheita das amostras}

MATERIAL E MÉTODOS

Vinte e três amostras de líquido amniótico de éguas sem raça definida foram colhidas em frigoríficos comerciais localizados na cidade de São Gabriel/ RS (3046'42" S, 5452'50" 0) e Araguari/ MG (18 $\left.39^{\circ} 4^{\prime \prime} \mathrm{S}, 48^{\circ} 11^{\prime} 7^{\prime \prime} 0\right)$. Os úteros foram abertos e, a partir da exposição do âmnio, amostras de $15 \mathrm{~mL}$ de líquido amniótico foram aspiradas com seringa agulhada estéril.

Durante as colheitas, realizou-se a mensuração da distância céfalococcígea (CC) de todos os fetos para realização da divisão das amostras de acordo com a idade gestacional (IG) segundo equação $I G=22,623+4,2528 C R-0,0124 C C^{2}$ sugerida por Naves et al (2008). Consideraram-se as amostras de terço inicial (TI) de gestação àquelas obtidas de gestações de até 110 dias; de terço médio de gestação (TM) as amostras de 110 dias até 220 dias; e de terço final de gestação (TF) as amostras de 220 dias em diante. 0 grupo TI totalizou em 8 amostras, o grupo TM em10 amostras e o grupo TF em 5 amostras.

Após a colheita, todas as amostras foram transferidas para tubos de centrífuga estéreis, armazenados e transportados a $5^{\circ} \mathrm{C}$ por até 72 horas até o laboratório localizado na cidade de Botucatu/SP (2253'09"S, 4826'42"0) no sistema de transporte refrigerado de sêmen Botutainer ${ }^{\circledR}$ (Botupharma, Botucatu, Brasil).

\section{Isolamento e cultivo}

Ao chegar ao laboratório, as amostras foram centrifugadas a 1750 RPM/10 min, o sobrenadante foi desprezado e o "pellet" ressuspendido em $4 \mathrm{~mL}$ do meio composto por $40 \%$ de DMEM baixa glicose, $40 \%$ de F12, 20\% de soro fetal bovino, anfotericina B, estreptomicina e penicilina (Gibco, Carisbad, USA). Cada amostra foi dividida em duas alíquotas de $2 \mathrm{~mL}$ e cultivadas em frascos de cultivo de $25 \mathrm{~cm}^{3}$ (Sarstedt, Nümbrecht, Alemanha), em estufa com $90 \%$ de umidade e $5 \%$ de $\mathrm{CO}_{2}$ a $37,5^{\circ} \mathrm{C}$. As amostras em cultivo foram suplementadas com meio inicialmente a cada cinco dias. Após a adesão das células, os meios foram trocados a cada 48-72 horas e as passagens foram realizadas quando do alcance de $80 \%$ de confluência. Para isto, as monocamadas foram lavadas duas vezes com $2 \mathrm{~mL}$ de tampão Salina-Fosfato (DPBS 1x, LGC Biotecnologia, BRA), foram adicionados $2 \mathrm{~mL}$ de Tripsina (TrypLE ${ }^{\mathrm{TM}}$ Express, Invitrogen, Carisbad, USA) e os frascos de cultivo mantidos na estufa por 5 minutos. Após a confirmação de que a dissociação entre as células havia ocorrido, as amostras foram centrifugadas e lavadas duas vezes no meio citado para completa remoção da tripsina. Os "pellets" foram então ressuspendidos em $10 \mathrm{~mL}$ de meio e divididos em duas alíquotas e recolocados em dois novos frascos de cultivo com $5 \mathrm{~mL}$ cada.

\section{Imunocitoquímica}

Após a passagem, as amostras foram cultivadas em placas 24 wells no meio de cultivo citado por 48 horas, quando apresentaram adesão e morfologia fibroblastóide. As células foram então fixadas (paraformoldeído 4\%) e permeabilizadas com saponina (Fix \& Perm fixation and permeabilization Kit, Invitrogen, Carisbad, USA), lavadas 3 vezes com PBS, incubadas com solução de lei- te desnatado a $3 \%$ por 1 hora para o bloqueio de proteínas inespecíficas, lavadas 3 vezes em PBS novamente e incubadas por 18 horas a $5^{\circ} \mathrm{C}$ com os anticorpos primários monoclonais mouse anti horse CD44, mouse anti human PCNA, vimentina e citoqueratina, e com o anticorpo policlonal goat anti Oct-4. Os anticorpos primários foram detectados por meio da incubação com os anticorpos secundários ligados a peroxidase (Advance, Dako, USA), exceto para o Oct-4, para o qual foi utilizado o anticorpo secundário anti goat por 30 minutos e o complexo ABC Kit Vectastain (Vector Laboratories Inc., CA, USA). As reações foram reveladas utilizando-se solução de substrato cromogênico - DAB por 5 minutos (Liquid DAB Cromogen $®$ - DakoCytomation, CA, USA).

\section{Citometria de fluxo}

Para a citometria de fluxo as amostras foram tripsinizadas e ressuspendidas em PBS. As amostras foram divididas em alíquotas e incubadas com os anticorpos, anti-CD90 e anti-CD34 conjugados com a sonda FITC e com o anticorpo primário anti-CD44 por uma hora, seguida da incubação com o anticorpo secundário conjugado com a sonda PE ou FITC por mais uma hora. Duas amostras de cada terço gestacional foram analisadas no citômetro FACS Calibur BD ${ }^{\circledR}$. Foram realizados os controles de autofluorescência das células e controle negativo para o CD44.

\section{Diferenciação}

Osteogênica. Para a diferenciação osteogênica, as amostras foram cultivadas em placas 6 "well". Quando as mesmas apresentaram cerca de $60 \%$ de confluência o meio de cultivo foi substituído pelo meio de indução de diferenciação osteogênica (StemPro Osteogenesis Kit, Gibco, USA). Foram realizadas trocas de meio a cada 48-72 horas por 14 dias. Para a avaliação da diferenciação, as monocamadas foram fixadas em paraformoldeído $4 \%$ por 30 minutos, lavadas duas vezes com água destilada e cobertas com a coloração Alizarin Red 2\% pH 4,2 (Sigma-Aldrich, USA) por 3 minutos. Após este período, foram lavadas mais duas vezes com água destilada e analisadas sob microscopia de luz invertida para observação de depósitos de matriz de cálcio, corados em vermelho.

Adipogênica. Para a diferenciação adipogênica, as monocamadas foram cultivadas em placas 6 "well" e quando as mesmas apresentavam $60 \%$ de confluência o meio de cultivo foi substituído pelo meio de indução de diferenciação adipogênica (StemPro Adipogenesis Kit, Gibco, USA). Foram realizadas trocas de meio a cada 48-72 horas por 10 a 14 dias. Para a avaliação da diferenciação, as monocamadas foram fixadas em paraformoldeído 4\% por 30 minutos, lavadas três vezes em PBS, seguida de duas vezes com água destilada e cobertas com a coloração Oil Red O (Sigma-Aldrich,USA) por 50 minutos. Após este período, foram lavadas mais duas vezes com água destilada e analisadas sob microscopia de luz invertida para observação gotículas de lipídeo intracitoplasmático, corados em vermelho.

Condrogênica. Para a diferenciação condrogênica, as monocamadas foram tripsinizadas e centrifugadas para obtenção do "pellet" de células. 0 cultivo foi realizado em tubos de centrífuga e os "pellets" foram mantidos por 24-48 horas no meio de manutenção quando o meio foi substituído pelo meio de indução de diferenciação condrogênica (StemPro Chondrogenesis Kit, Gibco, USA). Os meios foram trocados a cada 48-72 horas por 14 dias, e então foram fixados em formol tamponado e incluídos em parafina para realização dos cortes para formação de três lâminas por amostra, as quais foram coradas com Hematoxilina-Eosina (HE), Alcian Blue e Azul de Toluidina (Sigma-Aldrich,USA). As lâminas foram então observadas por microscopia de luz para avaliação da morfologia, presença de nódulos celulares entremeados por uma matriz extracelular de gliocosaminoglicanos que podem ser especificamente detectadas pelas colorações Alcian Blue e Azul de Toluidina. 


\section{Análise estatística}

Para análise estatística, a variável dependente binomial expressão das marcações (CD34, CD90 e CD44) na citometria fluxo dos diferentes grupos (terço inicial, médio e final da gestação) foi analisada por meio do teste de Regressão Logística utilizando o PROC LOGISTIC do SAS (SAS, Inst. Inc., Cary, NC, EUA). Quando o efeito de tratamento foi significativo utilizou-se o LSD com o comando LSMEANS PDIFF do PROC GLM do SAS. Fontes de variação no modelo incluindo os diferentes grupos experimentais foram consideradas como efeito fixo. Como efeito aleatório adotou-se os animais (grupo). Os resultados estão apresentados como porcentagem. Foi adotado o nível de significância de $5 \%(\mathrm{P}<0,05)$.

\section{RESULTADOS}

\section{Morfologia}

Todas amostras apresentaram adesão à superfície plástica do frasco de cultivo e morfologia fibroblastóide. As amostras provenientes do terço inicial, médio e final apresentaram adesão e morfologia fibroblastóide em 7 dias em média e permaneceram em cultivo primário por aproximadamente 21 dias, quando alcançaram confluência de $80 \% \mathrm{e}$ as passagens foram realizadas (Fig.1).

\section{Imunocitoquímica}

Todas as amostras dos períodos gestacionais foram avaliadas e apresentaram imunomarcação para os anticorpos anti CD44, PCNA e vimentina e ausência de marcação para os anticorpos anti citoqueratina e Oct-4.Todas as amostras estavam em terceira passagem (Fig.2).

\section{Citometria de fluxo}

Todas as amostras dos períodos gestacionais avaliadas apresentaram expressão de CD44, expressão de CD90 e au- sência de expressão do CD34. Os marcadores CD44 e CD90 demonstram padrão de expressão decrescente durante as fases gestacionais conforme demonstrado no Quadro 1 .

A expressão dos marcadores CD44, CD90, CD34 e os controles negativo do CD 44 e de autofluorescência das células fibroblastóides do líquido amniótico estão representadas nos gráficos da Figura 3 a seguir.

\section{Diferenciação}

Todas as amostras dos períodos gestacionais apresentaram capacidade de diferenciação osteogênica, adipogênica e condrogênica. As amostras estavam em segunda passagem (P2). Não foram observadas diferenças na capacidade de diferenciação entre as amostras obtidas do terço inicial, médio e final da gestação.

0 cultivo das LA-CTMs realizado em meio indutor de diferenciação osteogênica por 14 dias resultou na produção de cristais de cálcio extracelular identificados em vermelho pela coloração Alizarin Red (Fig.4A). As LA-CTMs cultivadas em meio indutor de diferenciação adipogênica por 14 dias apresentaram mudanças morfológicas tornando-se ar-

Quadro 1. Valores em porcentagem de expressão dos marcadores CD34, CD90, CD44 de células fibroblastóides derivadas do líquido amniótico equino colhido no terço inicial, médio e final da gestação

\begin{tabular}{ccccc} 
Marcação & $\begin{array}{c}\text { Grupo Terço } \\
\text { Inicial }\end{array}$ & $\begin{array}{c}\text { Grupo Terço } \\
\text { Médio }\end{array}$ & $\begin{array}{c}\text { Grupo Terço } \\
\text { Final }\end{array}$ & Valor de P \\
\hline CD34 & 2,0 & 1,8 & 2,7 & 0,8686 \\
CD90 & $96,5^{\mathrm{a}}$ & $68,9^{\mathrm{b}}$ & $34,3^{\mathrm{c}}$ & $<0,0001$ \\
CD44 & $96,6^{\mathrm{a}}$ & $91,7^{\mathrm{b}}$ & $86,9^{\mathrm{ab}}$ & 0,0337
\end{tabular}

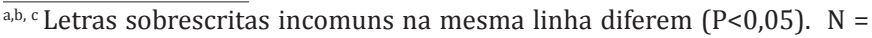
20.000 .
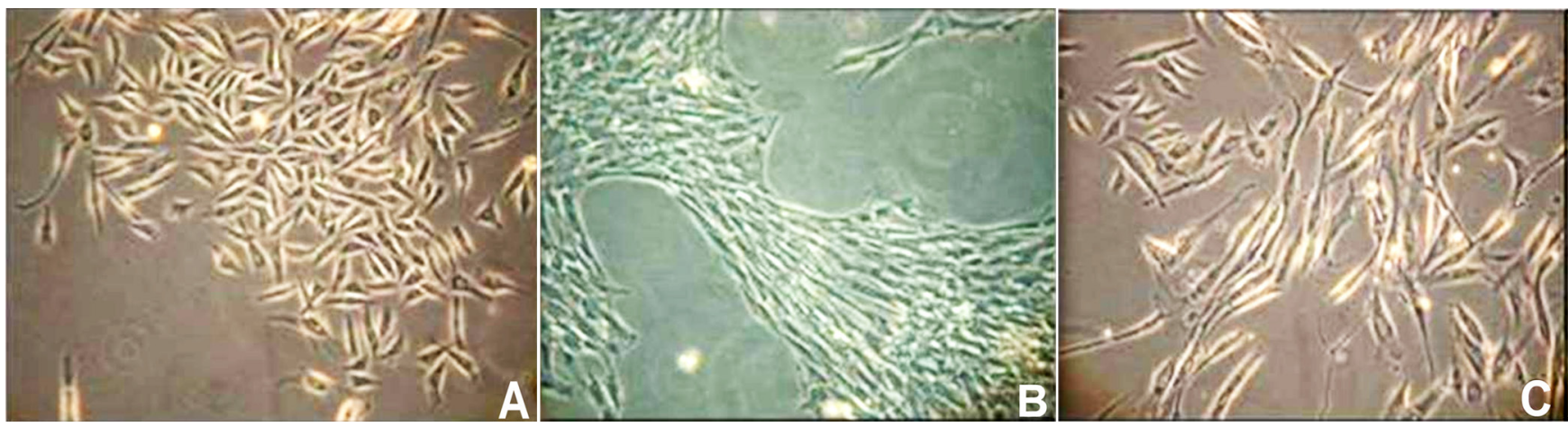

Fig.1. Cultivo primário de células aderentes com morfologia fibroblastóide derivadas do líquido amniótico equino colhidos de úteros gravídicos (A) no terço inicial, (B) médio, (C) final de gestação, aos 7 dias de cultivo.

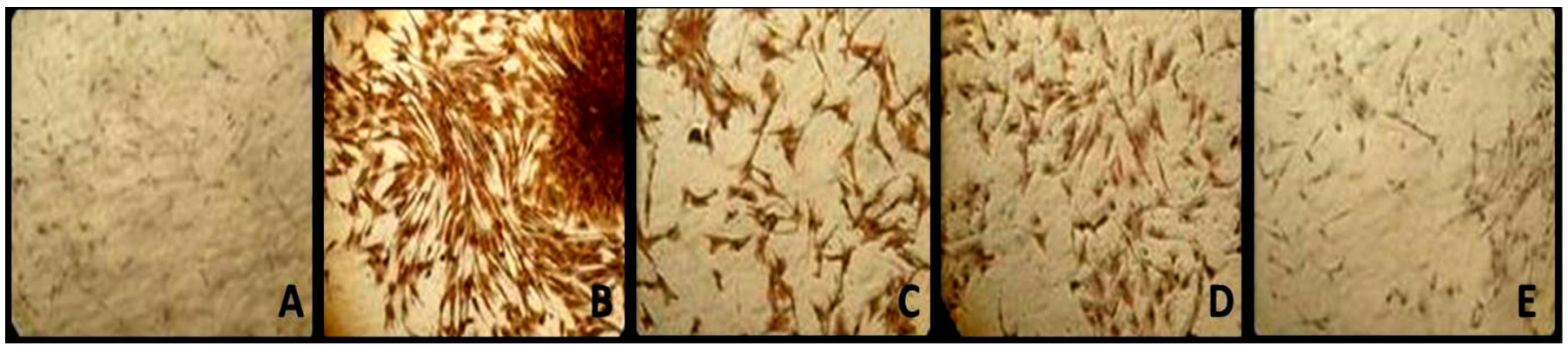

Fig.2. Células com morfologia fibroblastóide derivadas de amostras de líquido amniótico equino, imunocoradas para os anticorpos anti-CD44 (B), vimentina (C), PCNA(D) e com ausência de marcação para citoqueratina (A) e Oct-4 (E). 


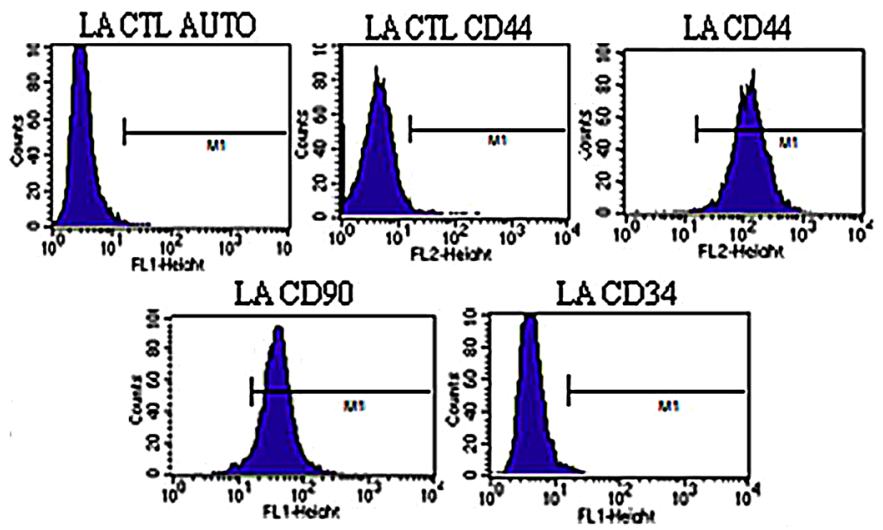

Fig.3. Gráficos da citometria de fluxo de amostra de células fibroblastóides derivadas de líquido amniótico (LA) equino colhido no terço inicial da gestação. Os gráficos demonstram a expressão CD44 e CD90, ausência de expressão do CD34, bem como o controle de autofluorescência das células e controle negativo do CD44.

redondadas e apresentaram o acúmulo de gotículas lipídicas em seu citoplasma coradas em vermelho pela coloração Oil Red O (Fig.4B,C). A análise histológica do cultivo em 3D das LA-CTMs sob meio indutor de diferenciação condrogênica por 14 dias apresentou células arredondadas cercadas de matriz de gliocasaminoglicanos (coradas em vermelho pela coloração HE, em azul pela coloração Alcian Blue e pelo fenômeno de metacromasia observado pela coloração Azul de Toluidina (Fig.4D-E).

\section{DISCUSSÃO}

A busca de novas fontes de células-tronco mesenquimais como alternativa à medula óssea foi crescente na última década principalmente na medicina humana. Neste sentido, os anexos fetais destacaram-se por serem fontes de fácil obtenção, de colheita não invasiva quando realizada ao nascimento e com grande possibilidade de formação de bancos de armazenamento na medicina humana (Fauza 2004, Gucciardo 2008) e veterinária (Cremonesi et al. 2011). No entanto, os estudos sobre a identificação de células-tronco mesenquimais derivadas do líquido amniótico equino são raros, tendo sido relatados apenas por Lovati et al. (2011), Park et al. (2011) e Lacono et al. (2012), utilizando amostras colhidas durante o parto.
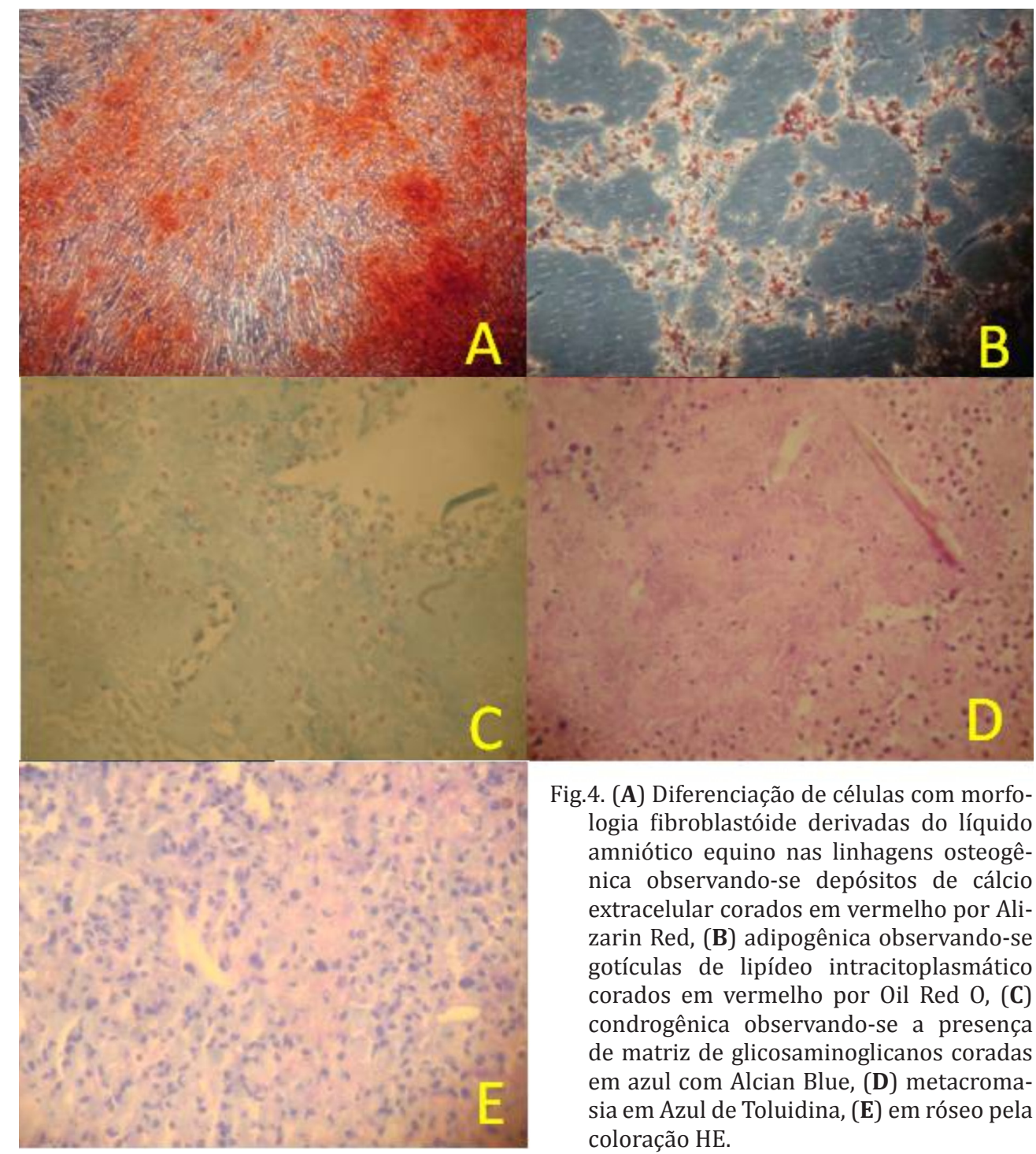

Fig.4. (A) Diferenciação de células com morfologia fibroblastóide derivadas do líquido amniótico equino nas linhagens osteogênica observando-se depósitos de cálcio extracelular corados em vermelho por Alizarin Red, (B) adipogênica observando-se gotículas de lipídeo intracitoplasmático corados em vermelho por Oil Red O, (C) condrogênica observando-se a presença de matriz de glicosaminoglicanos coradas em azul com Alcian Blue, (D) metacromasia em Azul de Toluidina, (E) em róseo pela coloração HE. 
Visando o surgimento de novos modelos terapêuticos para medicina veterinária regenerativa, principalmente para lesões dos cavalos atletas, nosso trabalho teve o objetivo de identificar CTMs derivadas do líquido amniótico equino colhido em diferentes momentos gestacionais e comparar suas características, bem como contribuir para otimização do isolamento, caracterização e diferenciação in vitro das mesmas. Os resultados deste estudo demonstraram que células-tronco mesenquimais podem ser isoladas do líquido amniótico colhido em qualquer fase da gestação equina, possibilitando a utilização de úteros gravídicos obtidos em frigoríficos comerciais como fonte de colheita de líquido amniótico para a formação de bancos de LA-CTMs. Sendo assim, estes resultados estão de acordo com Steigman et al. (2009) e You et al. (2009) que demonstraram que as CMTs do líquido amniótico do último terço gestacional de mulheres obtidos durante cesariana de fetos a termo, e não somente amostras obtidas do segundo terço gestacional, podem ser isoladas e cultivadas com sucesso.

As amostras de todos os grupos estudados apresentaram morfologia fibroblastóide e aderência ao plástico corroborando com os achados de Tsai et al. (2004) e You et al. (2009) na medicina humana, com Uranio et al. (2011) na medicina veterinária canina, Corradetti et al. (2013) na medicina veterinária bovina e ainda, com Park et al. (2011), Lovati et al. (2011) e Lacono et al. (2012) na medicina veterinária equina. Porém, tivemos uma dificuldade inicial no isolamento destas células a qual foi superada diminuindo-se o volume de meio utilizado no cultivo primário de $5 \mathrm{~mL}$ para $2 \mathrm{~mL}$ (deixando as células em suspensão mais próximas da superfície plástica do frasco de cultivo) e aumentando-se o tempo para a realização da primeira troca de meio de 2 dias para 7 dias (evitando-se o descarte de células com capacidade de aderência que ainda estivessem em suspensão). Neste contexto, Lacono et al. (2012) descreveram que células isoladas da gelatina de Wharton e sangue de cordão umbilical equino demonstraram maior taxa de expansão in vitro do que as células obtidas do líquido amniótico colhido no momento do parto, sendo que todos os grupos apresentaram características de CTMs, o que pode indicar uma maior dificuldade no cultivo in vitro destas células, corroborando com os nossos resultados.

$\mathrm{Na}$ análise imunocitoquímica realizada na placa de cultivo observou-se marcação positiva para CD44 e Vimentina e para o marcador de proliferação celular PCNA e ausência de marcação para Citoqueratina confirmando a origem mesenquimal e potencial de proliferação de todos os grupos colhidos no período gestacional, mantendo-se a morfologia característica das células. A ausência de marcação para Oct-4 discorda do encontrado na literatura tanto humana (Prusa et al.2004, Tsai et al. 2004, You et al. 2009), quanto veterinária equina (Lovati et al. 2011, Park et al. 2011) e bovina (Corradetti et al. 2013), porém está de acordo com Uranio et al. (2011) que relata a ausência de expressão de Oct-4 em CTMs derivadas do líquido amniótico canino.

É conhecido que no liquido amniótico encontra-se uma mistura de células e que as células com características epiteliais são aquelas com maior tendência a expressar os marcadores de pluripotência (Gucciardo et al. 2008). Cor- radetti et al. (2013) demonstraram que ambas as células derivadas da porção epitelial de membrana amniótica e líquido amniótico bovino apresentaram tanto expressão de marcadores de pluripotência como capacidade de diferenciação em linhagens ectodermais. Porém, sabe-se que com o avançar do tempo de cultivo, estas células tendem a ser eliminadas, permanecendo aquelas com características fibroblastóides. No entanto, no presente experimento, a avaliação foi realizada somente após a terceira passagem, desta forma, o número de passagens realizadas pode ter sido responsável pela eliminação, da população celular com características pluripotentes. Além disso, deve-se considerar ainda que a metodologia utilizada neste experimento difere da descrita na literatura e por ser uma avaliação qualitativa a observação de uma subpopulação positiva para Oct-4 pode ter sido prejudicada, sugerindo a necessidade de uma avaliação mais acurada, quantitativa como a citometria de fluxo. Entretanto, alguns autores alertam para o fato da detecção do sinal de Oct-4 e até de proteínas semelhantes ao Oct-4 serem resultado da transcrição de pseudogenes semelhantes a este fator e não do Oct-4 propriamente dito (Liedtke et al. 2007).

$\mathrm{Na}$ avaliação imunofenotípica por citometria de fluxo, todas as amostras avaliadas demonstraram expressão de CD44 (TI: 96,61\% ${ }^{\mathrm{a}}$; TM: $91,68 \%^{\mathrm{b}}$ e TF: $86,85 \%^{\mathrm{ab}}$ ), de CD90 (TI: $96,56 \%$; TM: $68,85 \%^{\mathrm{b}}$ e TF: $34,26^{\mathrm{c}}$ ) e ausência de expressão do marcador de células hematopoiéticas CD34: (TI: 1,95\%; TM: 1,83\% e TF: $2,74 \%$ ) corroborando com os resultados obtidos em humanos (Steigmann et al. 2008, You et al. 2009, Phermtai et al. 2010) e com a caracterização imunofenotipica das CTMs equinas sugeridas por De Schauwer (2011) e apresentadas por Lovati et al. (2011), Park et al. (2011) e Lacono et al. (2012) na avaliação de CTMs derivadas do líquido amniótico equino colhido no momento do parto. O CD90 tem sido considerado um dos principais marcadores de células-tronco hematopoiéticas (Mestas \& Hughes 2004, Majeti et al. 2007, Boitano et al. 2010), reconhecendo também CTMs (Masson et al. 2006), queratinócitos (Nakamura et al. 2006) e células progenitoras endometriais (Gargett 2006).

As maiores porcentagens de expressão do CD90 e do CD44 durante os períodos mais iniciais da gestação equina podem refletir as mudanças fisiológicas observadas durante a gestação e uma maior indiferenciação das CTMs nas fases iniciais da gestação equina. Este achado pode indicar as fases iniciais da gestação como melhor momento de colheita de amostras para obtenção de CTMs para formação de bancos de armazenamento de células, no entanto não inviabiliza a colheita nas fases finais da gestação e no momento do parto. Este aspecto ainda precisa ser melhor estudado, uma vez que de acordo com o nosso conhecimento, este é o primeiro trabalho que compara as características de células tronco obtidas do líquido amniótico em diferentes momentos da gestação na espécie equina.

Uma das propriedades biológicas mais importantes na caracterização das CTMs é a capacidade destas células em se diferenciarem em pelo menos 3 tecidos da linhagem mesenquimal. Desta forma, no presente experimento as amostras de todos os grupos estudados apresentaram 
capacidade de diferenciação osteogênica, adipogênica e condrogênica quando expostas aos respectivos meios indutores de diferenciação por 14 dias. Não foram observadas diferenças quanto a deposição de cálcio extra-celular, formação de gotículas de lipídeos intracitoplasmáticos e formação de matriz de gliocosaminosglicanos entre os períodos gestacionais estudados, já que metodologia utilizada não permitiu uma quantificação destes fatores. Pequenas diferenças quanto a estes fatores foram subjetivamente observadas entre as amostras, independentemente das fases gestacionais das quais eram provenientes. Estes resultados estão de acordo com os achados encontrados por Lovati et al. (2011), Park et al. (2011) e Lacono et al. (2012). Lovati et al. (2011) relataram que a capacidade de diferenciação condrogênica das CTMs derivadas do líquido amniótico equino foi menor do que a observada em CTMs derivadas da medula óssea e do tecido extra-vascular de cordão umbilical, no entanto, o mesmo tipo de comparação não foi realizado em nosso experimento.

\section{CONCLUSÕES}

Podemos concluir que as células fibroblastóides derivadas do líquido amniótico equino colhidas em qualquer fase gestacional possuem características morfológicas e imunofenotípicas de células-tronco mesenquimais, além de capacidade de diferenciação in vitro nas linhagens osteogênica, adipogênica e condrogênica, apresentando-se como uma fonte vantajosa, de coleta não invasiva, de CTMs para a terapia celular e medicina equina regenerativa.

As amostras colhidas em períodos gestacionais foram avaliadas apenas como instrumento de pesquisa, já que a amniocentese durante a gestação não é uma indicação de rotina para a espécie equina, dificultando sua aplicabilidade a campo. No entanto, amostras colhidas em frigoríficos comerciais podem constituir uma excelente fonte para formação de bancos.

O sucesso no isolamento de CTMs derivadas do líquido amniótico de amostras tranportadas refrigeradas a $5^{\circ} \mathrm{C}$ por até 72 horas pode viabilizar a colheita a campo e envio do material para o processamento em centros especializados.

Novos estudos quanto à expressão de marcadores de pluripotência como Oct-4, quanto à capacidade de diferenciação in vitro em linhagens extra-mesodermais das LA-CTMs e quanto ao uso autólogo e heterólogo destas células em terapias regenerativas devem ser realizados.

Agradecimentos.- Às agências FAPESP, Fundunesp e CAPES pelo apoio financeiro; aos Frigoríficos Pomar (Araguari, MG) e Frigorífico Foresta (São Gabriel, RS) pela colaboração na execução desta pesquisa.

\section{REFERÊNCIAS}

Antonucci I., Iezzi I., Morizio E., Mastrangelo F., Pantalone A., Mattioli-Belmonte M., Gigante A., Salini V., Calabrese G., Tetè S., Palka G. \& Stuppia L. 2009. Isolation of osteogenic progenitors from human amniotic fluid using a single step cultura protocol. BMC Biotechnol. 9:1-9.

Boitano A.E., Wang J., Romeo R., Bouchez L.C., Parker A.E. Sutton S.E, Walker J.R., Flaveny C.A., Perdew G.H., Denison M.S., Schultz P.G. \& Cooke M.P. 2010. Aryl hydrocarbon receptor antagonists promote the expansion of human hematopoietic stem cells. Science 329:1345-1348.

Bydlowski S.P., Debes A.A., Duarte S.A., Janz F.L., Cavaglieri R.C. \& Maselli
L.M. 2009. Células-tronco do líquido amniótico. Revta Bras. Hematol. Hemoterap. 31:45-52.

Cabral A.C.V., Ângelo P.C., Leite H.V., Pereira A.K., Lopes A.P.B.M., Oliveira M.B., Borges K.B.G., Pardini V.C. \& Ferreira A.C.S. 2009. Isolamento, diferenciação e aspectos bioquímicos de células-tronco de líquido amniótico. Revta Assoc. Med. Bras. 54:489-493.

Corradetti B., Meucci A., Bizzaro D., Cremonesi F., Lange-Consiglio A. 2013. Mesenchymal stem cells from amnion and amniotic fluid in bovine. Reproduction DOI:10.1530/REP-12-0437. (In publication)

Cremonesi F., Corradetti B. \& Lange-Consiglio A. 2011. Fetal adnexa derived stem cells from domestic animals: progress and perspectives. Theriogenology 75:1400-1415.

De Schauwer C., Meyer E., Van de Walle G.R. \& Soon A.V. 2011. Markers os stemness in equine mesenchyal stem cells: a plea for uniformity. Theriogenology 75:1431-1443.

Fauza D.O. 2044. Amniotic fluid stem cells. Best Pract. Res. Clin. Obstet. Gynaecol. 18:877-891.

Gargett C.E. 2006. Identification and characterisation of human endometrial stem/progenitor cells. Aust. N. Z. J. Obstet. Gynaecol. 46:250-253.

Gosden C.M. 1983. Amniotic fluid cell types and culture. Brit. Med. Bull. 39:348-354.

Gucciardo L., Lories R., Ochsenbeiri-Kölble N., Done E., Zwijsen A. \& Deprest J. 2008. Fetal mesenchymal stem cells: isolation, properties and potencial use in perinatology and regenerative medicine. Int. J. Obstet. Gynaecol. 16:166-172.

Lacono E., Brunori L., Pirrone A., Ricci F., Pagliaro P.P., Tazzari P.L., Merlo B. 2012. Isolation, characterization and differentiation of mesenchymal stem cells (MSCs) from amniotic fluid, cord blood and Wharton's jelly in the horse. Reproduction 143(4):455-468.

Lovati A.B., Corradetti B., Lange-Consigli A., Recordati C., Bonacina E., Bizzaro D. \& Cremonesi F. 2010. Comparison of equine bone marrow, umbilical cord, and amniotic fluid-derived progenitor cells. Vet. Res. Commun. 35:103-121.

Majeti R., Park C.Y. \& Weissman I.l. 2007. Identification of a hierarchy of multipotent hematopoietic progenitors in human cord blood Cell. Stem Cell 1(6):635-644.

Masson N.M., Currie I.S., Terrace J.D., Garden O.J., Parks R.W. \& Ross J.A. 2006. Hepatic progenitor cells in human fetal liver express the oval cell marker Thy-1. Am. J. Physiol. Gastrointest. Liver Physiol. 291:45-54.

Mestas J. \& Hughes C.C. 2004. Of mice and not men: differences between mouse and human immunology. J. Immunol. 172:2731-2738.

Nakamura Y., Muguruma Y., Yahata T., Miyatake H., Sakai D., Mochida J., Hotta T. \& Ando K. 2006. Expression of CD90 on keratinocyte stem/progenitor cells. Brit. J. Dermatol. 154:1062-1070.

Naves C.S., Vieira R.C., Diniz E.G., Jacomini J.O., Belleti M.E. \& Oliveira R. 2008. Desenvolvimento morfológico dos ovários em fetos equinos sem raça definida. Ciência Rural 38:416-422.

Park S.B., Seo M.S., Kang J.G., Chae J.S. \& Kang K.S. 2011. Isolation and characterization of equine amniotic fluid-derived multipotent stem cells. Cytotherapy13:341-349.

Passeri S., Nocchi F., Lamanna R. \& Lapi S. 2009. Isolation and expansion of equine umbilical cord-derived matrix cells (EUCMCs). Cell Biol. Int. 33:100-105.

Peister A., Deutsch E.R., Kolambbkar Y., Hutmacher D.W. \& Guldberg R.E. 2008. Amniotic fluid stem cells produce robust mineral deposits on biodegradable Scaffolds. Tissue Eng. A 15:3129-3138.

Phermthai T., Odglun Y., Julavijitphong S., Titapant V., Chuenwattana P., Vantanasiri C. \& Pattanapanyasat K. 2010. A novel method to derive amniotic fluid stem cell for therapeutic purposes. BMC Cell Biol. 11:1-9.

Prusa A.R. \& Hengstschlager M. 2002. Amniotic fluid cells and human stem cell research: A new connection. Med. Sci. Monit. 8:RA253-RA257.

Prusa A.R., Marton E., Rosner M., Bettelhein D., Lubec G., Pollack A., Bernaschek G. \& Hengstschlãger M. 2004. Neurogenic cells in human amniotic fluid. Am. J. Obstet. Gynecol. 191:309-314.

Siegel N., Rosner M., Hanneder M., Valli A. \& Hengstchläger M. 2007. Stem 
Cells in Amniotic Fluid as New Tools to Study Human Genetic Diseases. Stem Cell Rev. 3:356-364.

Steigman S.A., Armant M., Bayer-Zwirello L., Kao G.S., Silberstein L., Ritz J. \& Fauza D.O. 2008. Preclinical regulatorynvalidation of 3-stage amniotic mesenchymal stem cell manufacturing protocol. J. Pediat. Surg. 43:1164-1169.

Torricelli F., Brizzi L.B. \& Bernabei P.A. 1993. Indentification of hematopoietic progenitors cells in human amniotic fluid before $12^{\text {th }}$ week of gestation. Ital. J. Anat. Embryol. 98:118-126.

Tsai M.S., Lee J.L., Chang Y.J. \& Hwang S.M. 2004. Isolation of human multipotent mesenchymal stem cells from second-semester amniotic fluid using a novel model two-stage culture protocol. Human Reprod. 19:1450-1456.

Uranio F.M., Valentini L., Lange-Consiglio A., Caira M., Guaricci A.C., L'abbate A., Catachio C.R., Ventura M., Cremonesi F. \& Dell'aquila M.E. 2011. Isolation, proliferation, cytogenetic, and molecular characterization and in vitro differentiation potency of canine stem cells from adnexa: A comparative study os amniotic fluid, amnion and umbilical cord matrix. Mol. Reprod. Dev. doi: 10.1002/mrd.21311

You Q., Tong X., GuanY., Zhang D., Huang M., Zhang Y. \& Zheng J. 2009. The biological characteristics of human third semester amniotic fluid stem cells. J. Int. Med. Res. 37:105-112. 